\title{
Combined Application of Study Design and Case-based Learning Comprehensive Model in Epidemiology Teaching
}

\author{
Xiuquan Shi ${ }^{1,2, *}$, Yanna Zhou ${ }^{1}$, Haiyan Wang ${ }^{1}$, Tao Wang ${ }^{1}$, Chan $\mathrm{Nie}^{1} \&$ Shangpeng Shi ${ }^{1}$ \\ ${ }^{1}$ Department of Epidemiology and Health Statistics, School of Public Health, Zunyi Medical University, Zunyi, \\ Guizhou 563006, China \\ ${ }^{2}$ Center for Injury Research and Policy \& Center for Pediatric Trauma Research, The Research Institute at \\ Nationwide Children's Hospital, The Ohio State University College of Medicine, Columbus, OH 43205, USA \\ *Correspondence: Department of Epidemiology and Health Statistics, School of Public Health, Zunyi Medical \\ University, 6\# Xuefuxi Road, Xinpu new District, Zunyi City, Guizhou Province, China. E-mail: xqshi@zmc.edu.cn
}

Received: June 14, 2017

Accepted: July 4, 2017 Online Published: August 28, 2017

doi:10.5430/jct.v6n2p52

URL: https://doi.org/10.5430/jct.v6n2p52

\begin{abstract}
This paper aims to conduct the SD-CBL (study design with the case based learning, SD-CBL) in Epidemiology teaching and evaluate its effect. Students from five classes were recruited, and a combined comprehensive teaching model of SD-CBL was used in the "Injury Epidemiology" chapter, while other chapters in "Epidemiology" curriculum were using a teaching model of case based learning (CBL) only or single PowerPoint (ppt) teaching (it was considered as a traditional teaching in many universities). In the final of the semester, the effects of these three teaching models were compared in different majors and different students source. We found that SD-CBL comprehensive teaching model was better than ppt only and CBL teaching methods $(P<0.001, P=0.007)$, and the significant differences were found in the increased scoring rate between different majors and different students source $(P<0.001, P=0.015)$. Thus, we concluded that the SD-CBL teaching model is effective and worth to promote in "Epidemiology" teaching, especial in chapters of epidemiology application. Moreover, it is recommended to conduct SD-CBL teaching model in students, who are major in medicine and have good science basis.
\end{abstract}

Keywords: study design; $C B L$; $S D$-CBL; teaching model; epidemiology

\section{Introduction}

Epidemiology is a mandatory curriculum in the field of preventive medicine and public health, and it has become a basic subject of modern medicine. However, the "Epidemiology" curriculum often met a cold reception in medical students, yet called their less attention in the previous teaching. Besides that many students had less interest in the curriculum so that they paid inadequate attention. There were two important reasons resulted in the outcome. One reason was that this curriculum was too theoretical and difficult to learn, and the other reason was many teachers still used traditional teaching model which was too boring to college students (Caron, 2013; Keyes and Galea, 2014).

Hawick and colleagues revealed college faculty may unintentionally influence the content and processes of teaching and learning, through mixed messages and hidden meanings. Sending messages is the key approach in teaching and learning, especially in some curriculum reforms (Hawick et al. 2017). As traditional teaching model is often a one-way of message transferring from teachers to students, it is difficult to build a good interaction between teaching and learning in a same time, which will affect the final efficiency of the school education. Thus, it is essential to reform the teaching and studying model in medical education such as in "Epidemiology" curriculum teaching.

Currently, PBL (Problem-based learning, PBL) and CBL (Case-based learning, CBL) and other teaching and studying models have been partly used in many teaching reforms to improve the quality of higher education, so as in medical education (Nair, et al. 2013; To, et al. 2016). Based on the actual situation of our university, teacher-student ratio is insufficient (less than 1:10), and it is difficult to meet the requirements to carry out PBL. So CBL was considered as our in teaching reforms. We know that CBL should use typical cases, and this teaching method generally cites the curriculum-related cases which happened in the real life into learning, training students with professional skills and high level in self-study abilities. It is a good teaching and studying method to combine the 
theory and practice, improves the capability of cognitive and learning (Allchin, 2013; Da Silva and Dennick, 2010). However, single CBL teaching in "Epidemiology" curriculum also has some limitations, such as the "Epidemiology" curriculum is a highly practical subject, while undergraduate students have little experience, and they are difficult to understand the epidemic cases in the work of diseases control.

Considering the "Epidemiology" curriculum is a highly practical subject, we firstly conducted a new integrated teaching model of SD-CBL in three majors (preventive medicine, food quality and safety, health management) in our university. We hope that through reforming the teaching model, we can make the metaphysical theoretical knowledge become more specific and easier to categorization. Moreover, students' self-learning abilities, the ability to analyze and solve problems, and even creative learning could be significantly improved.

In this study, we hope to explore a new way of teaching and improve the quality of teaching "Epidemiology" curriculum. We conduct a new type of teaching and studying model named "study design combined with CBL" (SD-CBL) in students and we aim to test whether SD-CBL could get a better teaching effect than CBL only or ppt teaching only in "Epidemiology" curriculum in medical college students.

\section{Materials and Methods}

\subsection{Study Subjects}

Undergraduate students of Grade 2013 who major in preventive medicine (belongs to medicine (medical-related major), source of students is science and they have a relative good basis in science), food quality and safety (belongs to non-medical major, source of students is also science), health management (belongs to non-medical major, source of students is liberal arts) were cluster sampled as our teaching targets. A total of 234 college students from five classes were recruited, while their age ranged from 19 to 22 years old. Our textbook was "Epidemiology" (seventh edition, in Chinese) published by People's Health Publishing Press and the editor-in-chief was Siyan Zhan from Peking University, China. Other teaching and reading materials were unlimited.

\subsection{Teaching Methods}

\subsubsection{Introduction and Characteristics of SD-CBL}

It is well known that cases are essential elements in CBL teaching, while Epidemiology-related cases almost come from medical research. Thus, if tutors could tell students how to do study design, it would be benefit for conducting CBL. As injury epidemiology was my most important research field, I could combine my experience in the injury research with teaching, and I also cumulated many injury-related cases, so I could easily carry out SD-CBL in the teaching of "injury epidemiology" section (We should point out that there was no evidence that chapter of "Injury Epidemiology" was easy and more interesting than other chapters of "Epidemiology" curriculum). Generally speaking, teachers (tutors) should let students understand, before the deep exploration of injury mechanism and injury preventive measures, clear description of the injury phenomenon is the first step. Concrete to injury epidemiology, we should get the three-dimensional distribution (spatial, temporal and population) of injuries firstly (just as the report of racing injuries by Maeda et al. 2016), such as central time of the injury occurs, the geographical distribution and high-risk persons. In the teaching process of "Epidemiology" theory curriculum, according to the syllabus, the teacher (tutor) used SD-CBL teaching model in the chapter of "Injury Epidemiology" in all five classes in the same procedures. Detailed description of step process (Jamkar, et al. 2007) was listed in Figure 1.

Researchers all know that good study design must include three elements and four principles of the research (details see Figure 1), but most of the undergraduate students had not participated in research work. Before teaching the three-dimensional distribution of injuries, we needed to introduce some background knowledge based on the tutor's research (Shi, et al. 2014), told students how to collect the injury cases and other relevant information (for example, selection of the study objects, sampling method, etc.) to describe the three-dimensional distributions of injuries. After that, we further needed to explore the risk factors. Finally, based on our findings of the risk factors, conducting the effective prevention efforts was our ultimate goal (Cao, et al. 2015). In a word, the most difference between SD-CBL teaching model and CBL only is that SD-CBL should teach students some basic knowledge of study design firstly, which will help students to understand the research why the case should be and how to collect the information in the case. 

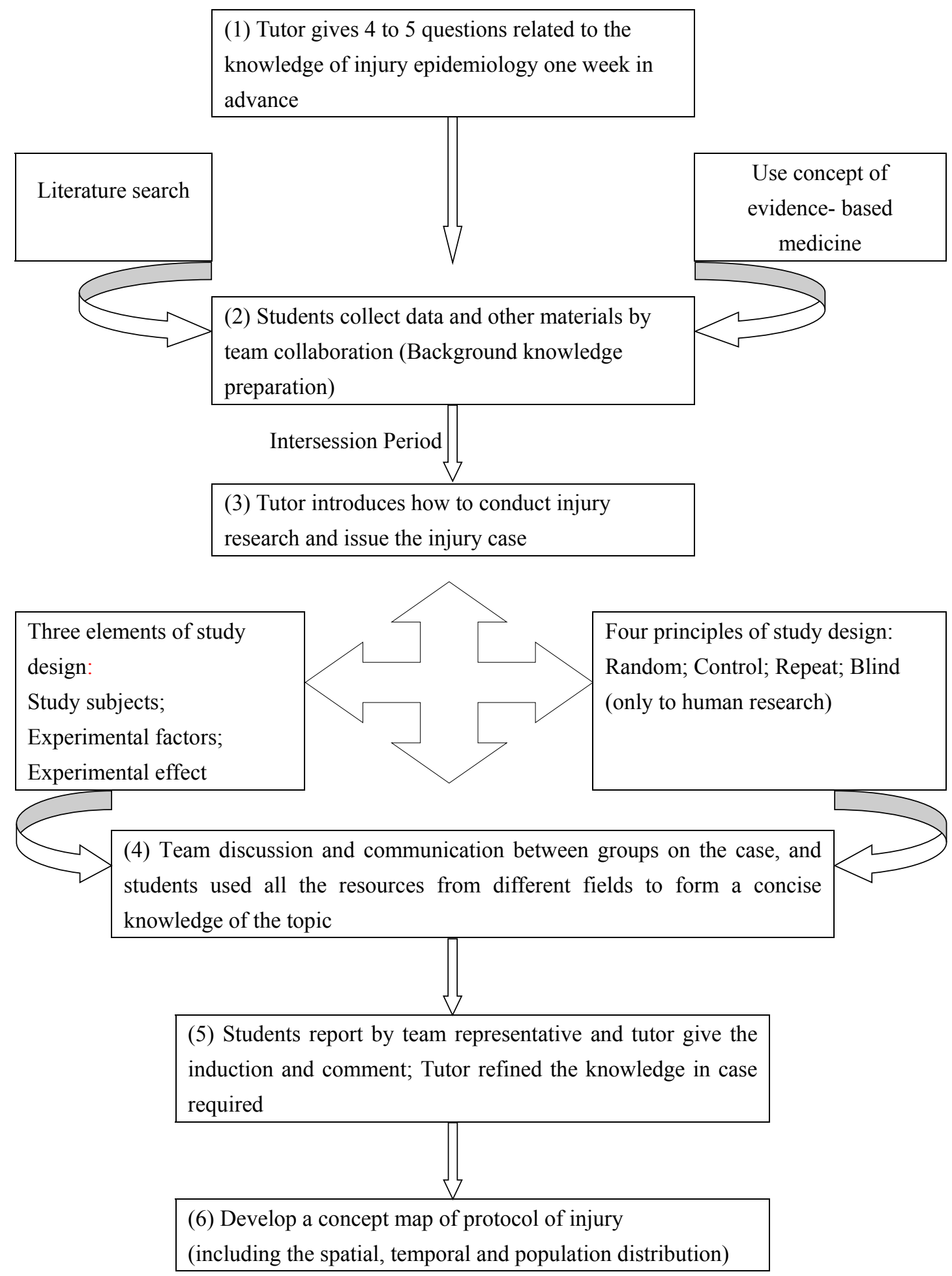

Figure 1. Learning Process of Study Design Combined with CBL

\subsubsection{Other Teaching Models}

In chapters other than "Injury Epidemiology" in "Epidemiology" curriculum, we used CBL only or ppt teaching (traditional teaching) methods as controls in the same classes. 


\subsection{Evaluated the Effect of Different Teaching Models}

We evaluated the effect of different teaching models through the following ways: (1) teaching effect surveyed or qualitative interviewed: According to the outlines, we recruited 20 students to talk about their experience /impressions/ suggestions of this new type of teaching model. The interviewing opinions can qualitatively reflect the effect of SD-CBL. All references (controls) in interviewing were the method of ppt teaching only in the other chapters in the same period of "Epidemiology" curriculum teaching. (2) Final examination.

\subsection{Statistical Methods}

All data analyzes were performed using SPSS software (Version 18.0, SPSS Company, Chicago, IL, USA), continuous data were described as "mean \pm standard deviation", difference comparisons were using the t-test and analysis of variance, and the trend test was also conducted; and categorical data were qualitative description as rate. $P<0.05$ was considered as statistically significant.

\section{Results}

\subsection{Qualitative Interviews of Different Teaching Models}

The qualitative interviews and group discussion showed that most students were willing to accept this new teaching model (SD-CBL). Compared with the ppt teaching only, all students (20/20) agreed that SD-CBL teaching method could obviously improve the followings: (1) To increase interests and enhance motivation in learning; (2) Better comprehending the role of epidemiology principles and methods in its application; (3) To improve students' abilities of literature search; (4) To improve students' abilities of analyzing, summarizing and solving the practical problems; (5) To enhance self-learning ability, and the expression and communication skills. In addition, part of the interviewed students agreed that the SD-CBL could help them to become more interested in medical research $(15 / 20)$ than the model of ppt teaching only. However, only part of students believed that SD-CBL can improve the scores of final examination (13/20). In summary, the overall satisfaction of SD-CBL was higher than the method of ppt teaching only.

\subsection{Comparison of the Scores of Final Examination}

Restricted by the syllabus, the absolute scores of the chapters were different among the teaching models of SD-CBL, the CBL only and ppt teaching only. Thus, all of our comparisons were not based on the absolute scores, but the scoring rate (\%).

Table 1. Scoring Rates in Different Teaching Models (mean \pm SD, \%)

\begin{tabular}{lccc}
\hline \multicolumn{1}{c}{ Teaching models } & $\begin{array}{c}\text { Scoring rates } \\
(\mathbf{n}=\mathbf{2 3 4})\end{array}$ & $\begin{array}{c}\text { Mean difference } \\
\text { and 95\% CI }\end{array}$ & P-value \\
\hline ppt teaching only & $63.89 \pm 12.11$ & 0 & 1.000 \\
CBL only & $69.70 \pm 13.89$ & $5.81(3.45,8.17)^{\mathrm{a}}$ & $<0.001^{\mathrm{a}}$ \\
SD-CBL & $72.81 \pm 11.02$ & $8.92\left(6.82,11.02^{\mathrm{a} /}\right.$ & $<0.001^{\mathrm{a} /}$ \\
Total & $68.05 \pm 10.16$ & $3.11(0.84,5.38)^{\mathrm{b}}$ & $0.007^{\mathrm{b}}$ \\
\hline
\end{tabular}

CBL: Case-based learning;

SD-CBL: study design combined with CBL teaching model;

${ }^{a}$ vs. ppt teaching only, $P<0.01$;

${ }^{\mathrm{b}}$ vs. CBL only, $P<0.01$;

${ }^{\mathrm{c}}$ trend test, $\mathrm{F}=60.58, P<0.001$.

Table 1 showed that the scoring rates of three teaching methods were significantly different $(\mathrm{F}=31.21, P<0.001)$. SD-CBL teaching method was significantly not only higher than ppt teaching only $(P<0.001)$, but also higher than that of the CBL teaching only $(P=0.007)$, and the scoring rate increased by $8.92 \%$ and $3.11 \%$, respectively. Moreover, the increasing of scoring rate among the three teaching models showed a linear trend (trend test, $\mathrm{F}=60.58$, $P<0.001)$. 
Table 2. Scoring Rates in Different Majors (mean \pm SD, \%)

\begin{tabular}{lccccc}
\hline Teaching models & $\begin{array}{l}\text { Major in Medicine } \\
\left(\mathbf{n}_{\mathbf{1}}=\mathbf{9 1}\right)\end{array}$ & $\begin{array}{c}\text { Major other than } \\
\text { Medicine }\left(\mathbf{n}_{\mathbf{2}}=\mathbf{1 4 3}\right)\end{array}$ & $\mathbf{t}$ & $\boldsymbol{P}$-value & $\begin{array}{c}\text { Mean Difference } \\
\text { and 95\% CI }\end{array}$ \\
\hline ppt teaching only & $66.44 \pm 11.66$ & $62.26 \pm 12.15$ & 2.604 & 0.010 & $4.18(1.02,7.34)$ \\
CBL only & $72.11 \pm 13.03$ & $68.16 \pm 14.24$ & 2.141 & 0.033 & $3.96(0.32,7.60)$ \\
SD-CBL & $76.45 \pm 11.65$ & $70.49 \pm 9.97$ & 4.033 & 0.000 & $5.96(3.04,8.88)$ \\
Total & $70.57 \pm 9.81$ & $66.45 \pm 10.09$ & 3.080 & 0.002 & $4.12(1.49,6.76)$ \\
\hline
\end{tabular}

Table 2 showed that the scoring rates of students major in the medicine were higher than the non-medical students in all three teaching models in our study (all $P<0.001$ ). Among them, the increasing value of scoring rate in SD-CBL teaching model was a little higher than that of ppt teaching only and teaching of CBL only.

Table 3. Scoring Rates in Different Students Source When They Were in High School (mean $\pm \mathrm{SD}, \%$ )

\begin{tabular}{|c|c|c|c|c|c|}
\hline \multirow[b]{2}{*}{ Teaching models } & \multicolumn{2}{|c|}{ Students source } & \multirow[b]{2}{*}{$\mathbf{t}$} & \multirow[b]{2}{*}{ P-value } & \multirow[b]{2}{*}{$\begin{array}{c}\text { Mean Difference and } \\
95 \% \mathrm{CI}\end{array}$} \\
\hline & $\begin{array}{l}\text { Science } \\
\left(n_{1}=142\right)\end{array}$ & $\begin{array}{c}\text { Liberal arts } \\
\left(\mathrm{n}_{2}=92\right)\end{array}$ & & & \\
\hline ppt teaching only & $65.79 \pm 11.26$ & $60.95 \pm 12.83$ & 3.043 & 0.003 & $4.85(1.71,7.99)$ \\
\hline CBL only & $71.40 \pm 12.56$ & $67.07 \pm 15.43$ & 2.250 & 0.026 & $4.33(0.53,8.12)$ \\
\hline SD-CBL & $74.21 \pm 10.82$ & $70.64 \pm 11.04$ & 2.443 & 0.015 & $3.57(0.69,6.44)$ \\
\hline Total & $69.72 \pm 9.38$ & $65.47 \pm 10.82$ & 3.181 & 0.002 & $4.24(1.62,6.87)$ \\
\hline
\end{tabular}

Table 3 showed that the scoring rates of students who source from (relatively good at) science in their high school were higher than those who source from liberal arts in their high school (all $P<0.001$ ). However, we also found that the difference of scoring rates between students' source from science and liberal arts in SD-CBL teaching model was lower than those using the ppt teaching only and CBL teaching only instead.

\section{Discussions}

At present, most of medical colleges still use the traditional model in "Epidemiology" teaching; teachers often use the simple ppt lecture in the theory teaching, and manage even control the class unilaterally. Thus, students felt the teaching process too boring to be enthusiasm in learning. Their abilities and skills of analyzing and resolving problems were also very poor as they lost interests to study hard in "Epidemiology" curriculum.

SD-CBL teaching model means using the "case-based learning" step by step in the teaching process, combining the cases with experience of study design in the scientific research, and simultaneously learning from the advanced concepts and methods in medicine teaching reforms in the western developed countries (Allchin, 2013; Da Silva and Dennick, 2010). Currently, PBL and CBL teaching and learning methods have been widely used in medical colleges in the United States, Australia and other Europe countries (Bosse, et al. 2010; Srinivasan, et al. 2007). In recent years, it has also been paid much attention in Chinese medical colleges, and these teaching methods also be widely used in medicine-related curriculums' teaching (Liu, et al. 2015).

From the qualitative feedback from part of students and the scoring rate of the final examination, both of them identified that the teaching model of SD-CBL has achieved good teaching effect. Other previous teaching methods often have some limitations, such as the distance teaching (Groenwold and Knol, 2013), electronic teaching (Gazibara, et al. 2015), because students have not reached to the stage of professional practice yet, and generally they are lack of thinking how to do application of the textbook, thus they are difficult to apply the knowledge into practice, while SD-CBL could overcome part of the deficiencies of the traditional teaching methods. There are also newer instruction models, such as blended or flipped classroom (Sajid, et al. 2016), but limited by a poor learning condition and curriculum characteristics, we not use in this study.

For the "Epidemiology" curriculum, as the results shown in Table 2 and Table 3, it should point out that, the effect of SD-CBL is better in students from medical-related majors than those from non-medical students. Moreover, the effect of SD-CBL is also better in science students in high school than those were liberal arts students in high school. Based on the curriculum of "Epidemiology", it is not only association to medicine, but also close association to the curriculum of "Health Statistics". (Both "Epidemiology" and "Health Statistics" are important tools in public health area; but generally speaking, science-students feel relatively easier to learn them than liberal arts students for their better basis on mathematics). Thus, our results suggested that when we conduct SD-CBL teaching method in 
"Epidemiology" in the future, in order to acquire a better teaching effect, we should try to choose students source from sciences in their high school (i.e. Students had a good basis in sciences such as mathematics, physical, chemistry; instead of good at politics, Chinese and history etc.).

In the process of SD-CBL, students play main roles in the study, including case analysis, case discussion and other case-related aspects. They should make full use of their knowledge, and by virtue of many learning skills as much as possible, such as concept mapping and/or mind mapping technique (Hung et al, 2015; Kalyanasundaram, et al, 2017). while the teacher only play a guiding role (tutor) in the teaching organization. At the same time, students also can develop good senses of cooperation (especially in literatures searching and case discussion), which will be beneficial for their future works. Moreover, this new teaching method is conducive to improve students' interests in study, expand the students' knowledge, and also to develop students' abilities to retrieve useful information after literature searching. Furthermore, as the study design is one essential part of SD-CBL process, it is important that SD-CBL also can stimulate students' scientific thinking, and require them to understand the study design, especial the procedure of data collection in a medical case, which can lay the foundation for their future research works, so medical students can quickly reach to the requirements of high-quality graduate in a relative short time.

This study has several limitations. First, no outer control or comparison groups were used during the period under investigation, only inner control was used to compare the effect of the different teaching models in this study. Moreover, considering our university did not have fixed teachers in the Epidemiology curriculum every year, and students from different grade might result to more heterogeneity which should affect the comparability of historical data, we also not used historical controls. Second, the outlines developed for the interviewing and survey were newly designed and might be only applied to this curriculum. Therefore, they lacked evidence of reliability and external validity (Moraros, et al. 2015). Finally, the findings of this study may not be generalizable to other non-medical curriculums and/or higher institution settings. Moreover, it required tutors more scientific research skills besides teaching skills in the SD-CBL teaching model.

\section{Conclusions}

Though we only collect preliminary evidence in the section of injury epidemiology, from the teaching practice, we conclude that the application of SD-CBL in "Epidemiology" teaching is feasible, especial in chapters of epidemiology application instead of epidemiology theory, and it is recommended that SD-CBL can be used as a new approach of teaching and even new ideas in education reform. However, this method of teaching still has some problems to be solved, such as the standardization (E.g. how to let poor basic students keep up with the steps of case discussion in class?) needs to be improved. Moreover, it requires teachers to have strong research skills and background knowledge before SD-CBL has been widely used. It still needs more exploration and practice in other curriculums, which are real challenges in the future.

\section{Acknowledgements}

The authors want to sincerely thank the undergraduate students for kindly agreeing to participate in this study. This study was supported by the first young middle-aged backbone teachers' plan of Zunyi Medical University (No.201604).

\section{Conflicts of Interest}

The authors declare no conflict of interest.

\section{References}

Allchin D. (2013). Problem- and case-based learning in science: an introduction to distinctions, values, and outcomes. CBE-Life Science Education, 12, 364-372. https://doi.org/10.1187/cbe.12-11-0190

Bosse HM., Huwendiek S., Skelin S., Kirschfink M., \& Nikendei C. (2010). Interactive film scenes for tutor training in problem based learning (PBL): dealing with difficult situations. BMC Medical Education, 10, 52. https://doi.org/10.1186/1472-6920-10-52

Cao BL., Shi XQ., Qi YH., Hui Y., Yang HJ., Shi SP., Luo LR., Zhang H., Wang X., \& Yang YP. (2015). Effect of a multi-level education intervention model on knowledge and attitudes of accidental injuries in rural children in Zunyi, southwest China. International Journal of Environment Research and Public Health, 12, 3903-3914. https://doi.org/ 10.3390/ijerph120403903 
Caron RM. (2013). Teaching epidemiology in the digital age: considerations for academicians and their students. Annual Epidemiology, 23, 576-579. https://doi.org/ 10.1016/j.annepidem.2013.06.001

Da Silva AL., \& Dennick R. (2010). Corpus analysis of problem-based learning transcripts: an exploratory study. Medical Education, 44, 280-288. https://doi.org/ 10.1111/j.1365-2923.2009.03575.x

Gazibara T., Marusic V., Maric G., Zaric M., Vujcic I., Kisic-Tepavcevic D., Maksimovic J., Maksimovic N., Denic LM., Grujicic SS., Pekmezovic T., \& Grgurevic A. (2015). Introducing E-learning in epidemiology course for undergraduate medical students at the faculty of medicine, University of Belgrade: a pilot study. Journal of Medical Systems, 39, 121. https://doi.org/10.1007/s10916-015-0302-7

Groenwold RH., \& Knol MJ. (2013). Learning styles and preferences for live and distance education: an example of a specialisation course in epidemiology. BMC Medical Education, $13,93$. https://doi.org/10.1186/1472-6920-13-93

Hawick L., Cleland J., \& Kitto S. (2017). Sending messages: How faculty influence professionalism teaching and learning. Medical Teacher, 39, 1-8. https://doi.org/ 10.1080/0142159X.2017.1337271

Hung CH., \& Lin CY. (2015). Using concept mapping to evaluate knowledge structure in problem-based learning. BMC Medical Education, 15, 212. https://doi.org/ 10.1186/s12909-015-0496-X

Jamkar AV., Burdick W., Morahan P., Yemul VY., \& Sarmukadum. Singh G. (2007). Proposed model of case based learning for training undergraduate medical student in surgery. Indian Journal of Surgery, 69, 176-183. https://doi.org/ 10.1007/s12262-007-0016-2

Kalyanasundaram M., Abraham SB., Ramachandran D., Jayaseelan V., Bazroy J., Singh Z., \& Purty AJ. (2017). Effectiveness of mind mapping technique in information retrieval among medical college students in Puducherry-a pilot study. Indian Journal of Community Medicine, 2(1), 19-23. https://doi.org/10.4103/0970-0218.199793

Keyes KM., \& Galea S. (2014). Current practices in teaching introductory epidemiology: How we got here, where to go. American Journal of Epidemiology, 180, 661-668. https://doi.org/ 10.1093/aje/kwu219

Liu WX., Zhang P., Zhang XL., Gao X., Li T., \& Yang L. (2015). Exploration of the application of PBL and CBL comprehensive teaching methods in epidemiology teaching. Education Teaching Forum, 8, 162-164.

Maeda Y., Hanada M., \& Oikawa M. (2016). Epidemiology of racing injuries in Thoroughbred racehorses with special reference to bone fractures: Japanese experience from the 1980s to 2000s. Journal of Equine Science, 27, 81-97. https://doi.org/10.1294/jes.27.81

Moraros J., Islam A., Yu S., Banow R., \& Schindelka B. (2015). Flipping for success: evaluating the effectiveness of a novel teaching approach in a graduate level setting. BMC Medical Education, $15,27$. https://doi.org/10.1186/s12909-015-0317-2

Nair SP., Shah T., Seth S., Pandit N., \& Shah GV. (2013). Case based learning: a method for better understanding of biochemistry in medical students. Journal of Clinical Diagnostic Research, 7, 1576-1578. https://doi.org/10.7860/JCDR/2013/5795.3212

Sajid MR., Laheji AF., Abothenain F., Salam Y., AlJayar D., \& Obeidat A. (2016). Can blended learning and the flipped classroom improve student learning and satisfaction in Saudi Arabia? International Journal of Medical Education, 7, 281-285. https://doi.org/ 10.5116/ijme.57a7.83d4

Shi XQ., Qi YH., Shi D., Yan C., Shi JX., Cao BL., Liu D., Luo LR., \& Wang HY. (2014). Features and risk factors of nonfatal injury among the rural c: a survey of seven schools in a mountain area in southwest China. PLoS ONE, 9, e102099. https://doi.org/10.1371/journal.pone.0102099

Srinivasan M., Wilkes M., Stevenson F., Nguyen T., \& Slavin S. (2007). Comparing problem-based learning with case-based learning: effects of a major curricular shift at two institutions. Academic Medicine, 82, 74-82. https://doi.org/ 10.1097/01.ACM.0000249963.93776.aa

To MJ., MacLeod A., \& Hwang SW. (2016). Homelessness in the medical curriculum: an analysis of case-based learning content from one Canadian medical school. Teaching and Learning in Medicine, 28, 35-40. https://doi.org/10.1080/10401334.2015.1108198 